\title{
Effect of Biosynthesized ZnO Nanoparticles on Multi-Drug Resistant Pseudomonas Aeruginosa
}

\author{
Syed Ghazanfar Ali ${ }^{1, *}$, Mohammad Azam Ansari ${ }^{2, *} \mathbb{1}$, Mohammad A. Alzohairy ${ }^{3}$, \\ Mohammad N. Alomary ${ }^{4}{ }^{\circ}$, Mohammad Jalal ${ }^{1}$, Sami AlYahya ${ }^{5}$, Sarah Mousa Maadi Asiri ${ }^{6}$ \\ and Haris M. Khan ${ }^{1}$ \\ 1 Department of Microbiology, Nanotechnology and Antimicrobial Drug Resistance Research Laboratory, \\ Jawaharlal Nehru Medical College and Hospital, Aligarh Muslim University, \\ Aligarh 202002, Uttar Pradesh, India; jalalmicro1981@gmail.com (M.J.); harismk2003@hotmail.com (H.M.K.) \\ 2 Department of Epidemic Disease Research, Institute for Research \& Medical Consultations (IRMC), \\ Imam Abdulrahman Bin Faisal University, P.O. Box 1982, Dammam 31441, Saudi Arabia \\ 3 Department of Medical Laboratories, College of Applied Medical Sciences, Qassim University, \\ Qassim 51431, Saudi Arabia; dr.alzohairy@gmail.com \\ 4 National Center for Biotechnology, Life Science and Environmental Research Institute, King Abdulaziz City \\ for Science and Technology, P.O. Box 6086, Riyadh 11442, Saudi Arabia; malomary@kacst.edu.sa \\ 5 National Center for Biotechnology, King Abdulaziz City for Science and Technology, P.O. Box 6086, \\ Riyadh 11442, Saudi Arabia; salyahya@kacst.edu.sa \\ 6 Department of Biophysics, Institutes for Research and Medical Consultations (IRMC), Imam Abdulrahman \\ Bin Faisal University, Dammam 31441, Saudi Arabia; smasiri@iau.edu.sa \\ * Correspondence: syedmicro72@gmail.com (S.G.A.); maansari@iau.edu.sa (M.A.A.)
}

Received: 28 April 2020; Accepted: 15 May 2020; Published: 17 May 2020

check for updates

\begin{abstract}
Synthesis of nanoparticles using the plants has several advantages over other methods due to the environmentally friendly nature of plants. Besides being environmentally friendly, the synthesis of nanoparticles using plants or parts of the plants is also cost effective. The present study focuses on the biosynthesis of zinc oxide nanoparticles ( $\mathrm{nnO}$ NPs) using the seed extract of Butea monsoperma and their effect on to the quorum-mediated virulence factors of multidrug-resistant clinical isolates of Pseudomonas aeruginosa at sub minimum inhibitory concentration (MIC). The synthesized ZnO NPs were characterized by different techniques, such as Fourier transform infra-red spectroscopy (FTIR), scanning electron microscopy (SEM), energy dispersive X-ray (EDX), and transmission electron microscopy (TEM). The average size of the nanoparticles was $25 \mathrm{~nm}$ as analyzed by TEM. ZnO NPs at sub MIC decreased the production of virulence factors such as pyocyanin, protease and hemolysin for P. aeruginosa $(p \leq 0.05)$. The interaction of NPs with the $P$. aeruginosa cells on increasing concentration of NPs at sub MIC levels showed greater accumulation of nanoparticles inside the cells as analyzed by TEM.
\end{abstract}

Keywords: P. aeruginosa; multidrug-resistant; quorum sensing; virulence factor; pyocyanin; ZnO NPs

\section{Introduction}

Pseudomonas aeruginosa is an opportunistic pathogen which attacks individuals suffering from different diseases including cancer, AIDS, and cystic fibrosis, as well patients who have medical implants or burn victims [1-4]. It is a very common pathogen that develops resistance against antibiotics and overcomes antibiotic treatment $[5,6]$. P. aeruginosa confers its pathogenesis and develops multidrug resistance through Quorum sensing [7]. Quorum sensing is a cell to cell communication responsible for different virulence gene expressions such as pyocyanin, proteases, toxins, and biofilm. Different compounds that interfere with this bacterial cell to cell communication are known as quorum 
quenchers, and these quorum quenchers attenuate the expressions of virulence genes responsible for proteases, toxins, siderophores, swarming and biofilm formation [8]. Quorum quenchers do not interfere with growth, and hence there is the least probability of development of resistance against them $[9,10]$.

Nanotechnology is an emerging field since it has applications in science and technology for manufacturing new materials at the nanoscale level [11]. Nanotechnology at present is not only confined to the electronics, rather these nanoparticles posses a role in catalysis, magnetism, optical, and antimicrobial aspects [12,13], beside their application in wound healing and anti-inflammatory effects [14]. Metal oxide-like zinc oxide nanoparticles during the last few years have drawn great attention due to their stability and ability to overcome harsh environmental conditions. They can be easily fabricated even at low temperature via reflux digestion process [15] and are considered to be safe for human beings and animals $[16,17]$. Zn compounds have been currently listed as GRAS, generally regarded as safe by the US Food and Drug Administration (21CFRI82.8991).

There are different methods for the synthesis of nanoparticles including physical and chemical methods. Chemical and physical methods besides being costly require extensive labor, time, and also generate a large quantity of secondary waste from the chemical agents used for the precipitation and reduction. The green method of synthesis of nanoparticles has advantages over other methods including being cost efficient and eco-friendly. Since the green method of synthesis uses plant material as a capping agent so no adverse effect would be seen during medical applications [18]. Synthesis of different metal nanoparticles using different parts of plant extracts are well documented in the literature such as leaves of Azadirachta indica [19], leaves of Putranjiva roxburghii [20], stem of Tinospora cordifolia [21], coir of Coccus nucifera [22], Bark of Crataeva nurvala [23], bark extract of Holarrhena pubescens [24].

Butea monosperma (Lam.) Kuntze (BM) is commonly known as Flame of forest, because of its red colored flowers and belongs to the family Fabaceae. Single seed at the end locus is found inside the Pod and the length of each pod is around $10-15 \mathrm{~cm}$. Due to their diverse nature, B. monosperma seeds were selected for the synthesis of ZnO NPs. Since the seeds of B. monosperma are found inside the pods which fall down and contribute toward the waste material, therefore, we included seeds in this study. Furthermore, these biosynthesized zinc oxide nanoparticles were characterized by different sophisticated techniques, and further their effect on to the quorum sensing regulated virulence factors in P. aeruginosa was investigated.

\section{Materials and Methods}

\subsection{Preparation of Aqueous Seed Extract of B. monosperma}

The seeds of $B$. monosperma were obtained from the pods and in each pod a single seed was present. Seeds were collected from different pods and sun dried to remove the water content. The air dried seeds were crushed and ground to the fine powder. $10 \mathrm{~g}$ of powder was dissolved in $100 \mathrm{~mL}$ of sterile water, and then the aqueous extract was filtered using Whatman No. 1 filter paper (Maidstone, UK) and finally passed from $0.22 \mu \mathrm{m}$ filter (Millipore). The centrifugation at $1200 \mathrm{rpm}$ for $5 \mathrm{~min}$ removed the heavy biomaterials and extract in aqueous form was stored at $4{ }^{\circ} \mathrm{C}$ for further use.

\subsection{Synthesis of B. monosperma Zinc Oxide Nanoparticles (BM-ZnO-NPs)}

Different volume (10 $\mathrm{mL}$ to $40 \mathrm{~mL}$ ) of aqueous extract of $B$. monosperma seeds were mixed with $1 \mathrm{mM}$ Zinc nitrate hexahydrate solution. The reaction mixture was heated $\left(60^{\circ} \mathrm{C}\right)$ for $3-4 \mathrm{~h}$ until cream colored precipitate was not obtained. This cream color precipitate was further centrifuged at $3000 \mathrm{rpm}$ for $15 \mathrm{~min}$ and the resulting pellet now obtained was collected in glass plate which was oven dried at $45^{\circ} \mathrm{C}$ for $24-48 \mathrm{~h}$. After complete drying, the powder obtained was further ground using mortar and pestle. The Diagrammatic representation of overall process of formation of $\mathrm{ZnO} N P s$ using B. monosperma seeds is represented in Figure 1. 


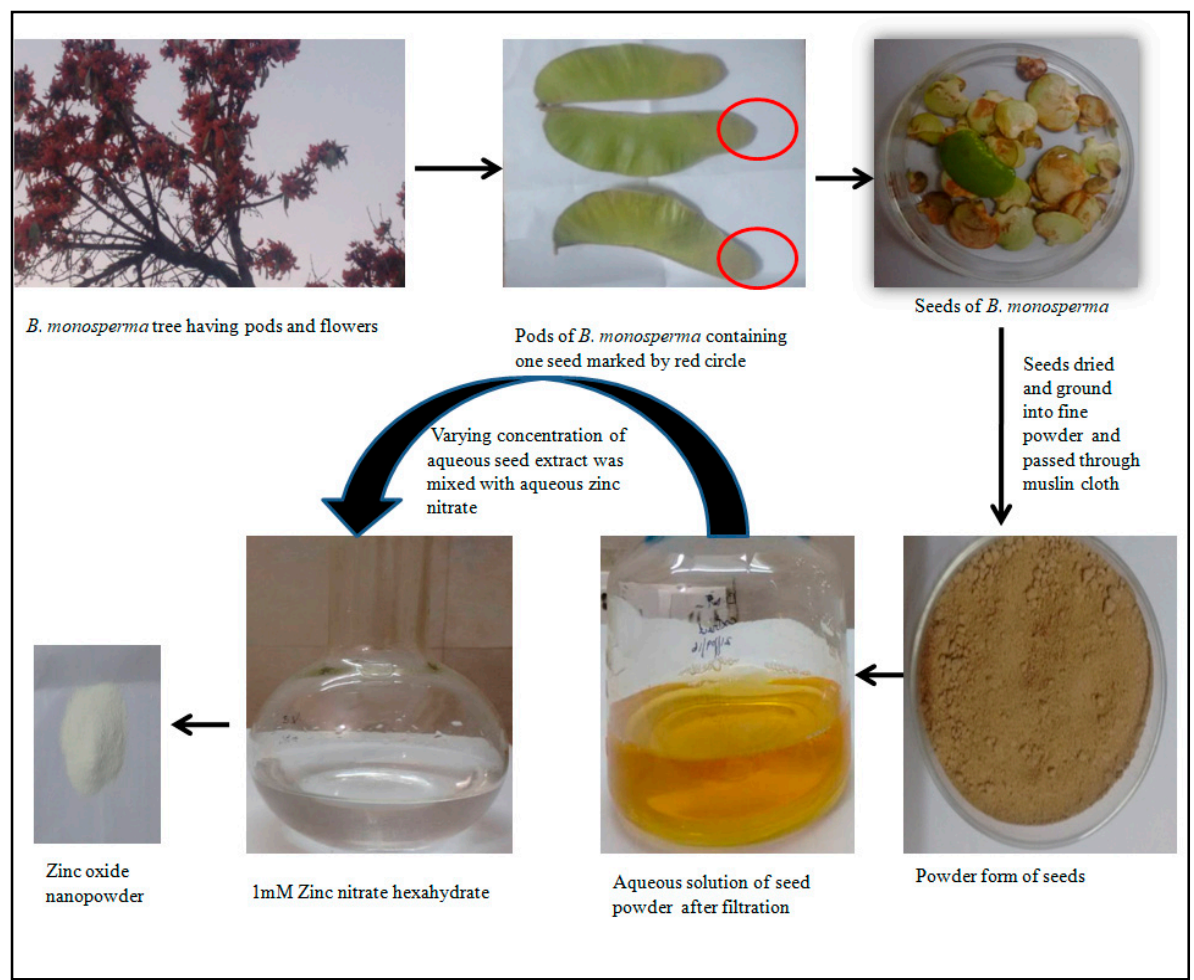

Figure 1. Diagrammatic representation of overall process of formation of ZnO NPs using Butea monosperma seeds.

\subsection{Characterization of Synthesized BM-ZnO-NPs by FT-IR}

FTIR spectrum was recorded using Perkin Elmer spectrophotometer spectrum in the range of $4000-400 \mathrm{~cm}^{-1}$ at room temperature $\left(25-35^{\circ} \mathrm{C}\right)$. The adsorption spectrum displayed different peaks representative of various bonds formed.

\subsection{Scanning Electron Microscopy (SEM) and Energy Dispersive X-ray (EDAX)}

To determine the morphology, distribution of nanoparticles and elemental composition of synthesized NPs, SEM equipped with EDAX(INCAx-actSN:56756) was performed. A thin film of nanoparticles was formed onto the glass coverslips by spreading the nanoparticles on to it, the samples were gold coated using gold coating sputter, and then the films were analyzed at an accelerating voltage of $15 \mathrm{KV}$.

\subsection{Transmission Electron Microscopy (TEM)}

The size and shape of the nanoparticles was further determined using TEM (Jeol 2100). Briefly, a copper grid was used onto which the sample (drop of nanoparticles) was placed, which was illuminated using electronic radiation under vacuum. Furthermore, the images were captured using electron beam transmitted through the sample [25].

\subsection{Bacterial Isolates}

P. aeruginosa $(N=10)$ were isolated from the patients' samples (urine, pus, etc.) received in the department of Microbiology J.N. Medical College and Hospital. The P. aeruginosa were identified by using various biochemical tests and individual isolates were tested for the antibiotic sensitivity based on the recommendation of clinical and laboratory standards institute [26]. PAO1 was used as a standard. 


\subsection{Determination of Minimum Inhibitory Concentration (MIC) of ZnO NPs}

Minimum inhibitory concentration of synthesized $\mathrm{ZnO}$ NPs was determined against $P$. aeruginosa by using two-fold macro broth dilution method as previously described [25]. Initially, P. aeruginosa colonies from overnight grown nutrient agar plates were used to inoculate the broth. Fresh overnight grown culture of $P$. aeruginosa $\left(2 \times 10^{6} \mathrm{CFU} / \mathrm{mL}\right)$ was used to inoculate each tube which was two-fold serially diluted with $\mathrm{ZnO}$ NPs at different concentration.

\subsection{Inhibition of Quorum-Mediated Virulence Factors by BM-ZnO NPs}

\subsubsection{Pyocyanin Assay}

The effects of synthesized $\mathrm{ZnONPs}$ on the production of virulence factor pyocyanin by P. aeruginosa were investigated using the methods described by Ali et al. [23] and Essar et al. [27]. Freshly grown overnight culture of P. aeruginosa was used to inoculate nutrient broth $(5 \mathrm{~mL})$ with or without varying concentration of BM-ZnO NPs in shaking incubator at $200 \mathrm{rpm}$. After incubation for $16 \mathrm{~h}$ at $37^{\circ} \mathrm{C}$, pyocyanin from the cell-free supernatant of the BM-ZnO-NPs treated and untreated P. aeruginosa culture was extracted with $3 \mathrm{~mL}$ chloroform and then re-extracted into $1 \mathrm{~mL} 0.2 \mathrm{~N} \mathrm{HCl}$ and the absorbance was measure at $520 \mathrm{~nm}$. The concentration of pyocyanin $(\mu \mathrm{g})$ produced per $\mathrm{ml}$ of culture supernatant was determined by multiplying the optical density $520 \mathrm{~nm}$ by 17.072 .

\subsubsection{Protease Assay}

The protease assay was performed as described by Quiblier et al. [28] with slight modifications. Briefly, skim milk (5 gm) and bacteriological agar $(0.5 \mathrm{gm})$ in $50 \mathrm{~mL}$ distilled water was amended with varying concentration of nanoparticles in different plates. Control plates were not amended with nanoparticles. An overnight grown culture of P. aeruginosa was put in the well of each plate and incubated overnight. Zone of clearance was measured [29]. Nutrient Broth was also added in each plate to check the proteolysis efficacy due to culture media.

\subsubsection{Hemolysis Assay}

Hemolytic analysis was performed as described by Saghalli et al. [30] with slight modification. Initially, blood agar plates were prepared with 5\% blood and 1\% agar amended with the varying concentration of BM-ZnO-NPs and control plates were not amended with nanoparticles. Wells in the plates were punched, and gaps were sealed by soft agar. The overnight grown culture of P. aeruginosa including PAO1 was poured in wells in equal quantity in both the plates. Nutrient broth was also poured in both the plates to check the hemolysis due to media.

\subsection{TEM Analysis Showing Localization of BM-ZnO NPs Inside Bacterial Cell}

The effects and internalization of BM-ZnO NPs on P. aeruginosa cells before and after treatment has been analyzed by using TEM. The preparation of sample for TEM analysis such as fixation, dehydration, drying, coating, and imaging was performed as protocol described by Ansari et al. [25].

\section{Results}

\subsection{FTIR Analysis}

The FTIR spectra at $10 \mathrm{~mL}$ extract concentration showed two different peaks at 1632, 3464 which represent $-\mathrm{C}=\mathrm{O}$ stretching, $-\mathrm{OH}$ stretching whereas $20 \mathrm{~mL}$ extract concentration showed 4 intense peaks at $826,1385,1685$, and 3381 correspondent to -C-H out of plane, $-\mathrm{N}-\mathrm{O}$ (nitro), $-\mathrm{NH}_{2}$ wagging,-and $\mathrm{NH}$ stretch, respectively. Extract concentration at $30 \mathrm{~mL}$ showed three distinct peaks at 1384, 1627, 3478 , representing $\mathrm{N}-\mathrm{O}$ (nitro), $-\mathrm{C}=\mathrm{O}$ (stretch), $-\mathrm{O}-\mathrm{H}$ (stretch). $40 \mathrm{~mL}$ extract concentration also showed 3 peaks at 1385, 1632, 3473 for $-\mathrm{N}-\mathrm{O}$ (nitro), $-\mathrm{C}=\mathrm{O}, \mathrm{O}-\mathrm{H}$ (stretch), respectively (Figure 2). 


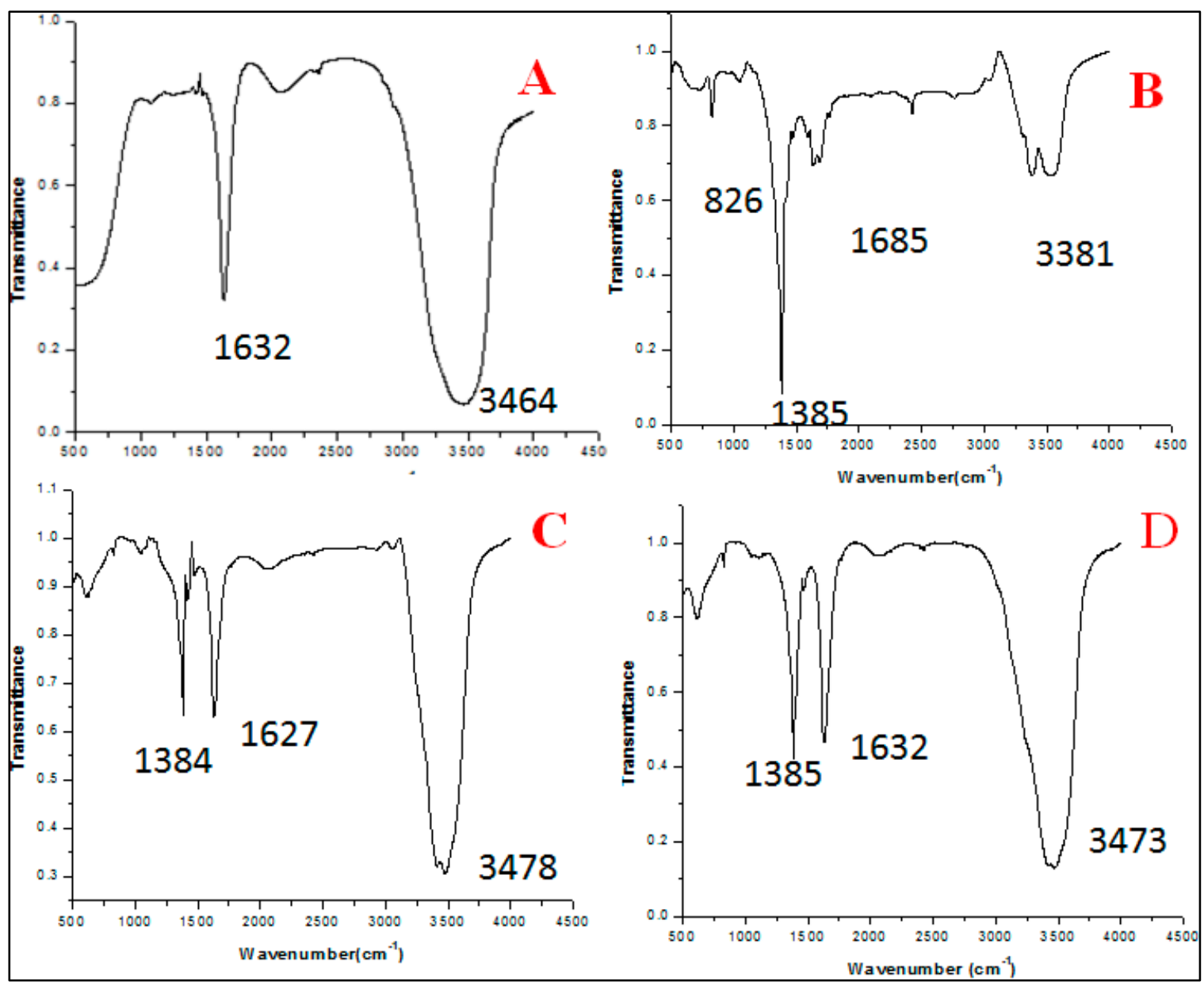

Figure 2. FTIR analysis between $4500-500 \mathrm{~cm}^{-1}$ showing different peaks which are representative of different bonds formed during the synthesis of zinc nanoparticles at different concentration of extract.

(A) $10 \mathrm{~mL}$ extract, (B) $20 \mathrm{~mL}$ extract, (C) $30 \mathrm{~mL}$ extract, and (D) $40 \mathrm{~mL}$ extract.

\subsection{SEM and EDAX Analysis}

SEM analysis of nanoparticles at different concentration of extract showed the distribution of nanoparticles and their elemental composition was quantified by EDAX. SEM showed that nanoparticles at lower extract concentration $(10 \mathrm{~mL})$ were more clumped whereas on increasing the extract concentration segregation was seen, and at the highest concentration $(40 \mathrm{~mL})$ greatest segregation of nanoparticles was seen and individual nanoparticles were more clear (Figure 3). EDAX analysis showed that as the extract concentration increases the greater amount of $\mathrm{ZnO}$ NPs were formed, it is evident from the graphical analysis that at $10 \mathrm{~mL}$ of extract concentration $6.12 \%$ of zinc was analyzed whereas at $40 \mathrm{~mL}$ extract the number increased to $12.53 \%$ (Figure 4 ). 


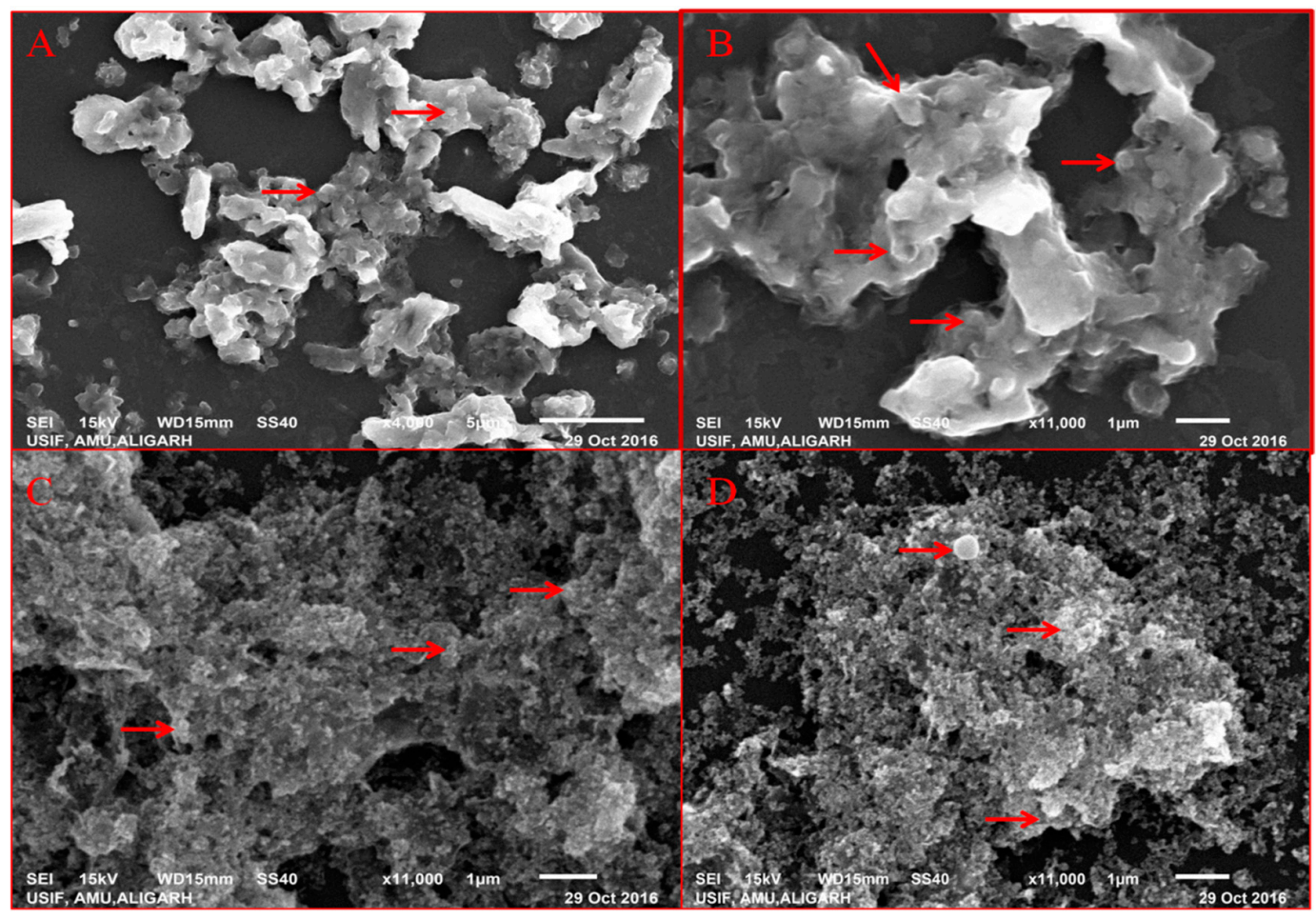

Figure 3. SEM of BM-ZnO NPs at different concentration of extract. (A) $10 \mathrm{~mL},(\mathbf{B}) 20 \mathrm{~mL},(\mathbf{C}) 30 \mathrm{~mL}$, (D) $40 \mathrm{~mL}$ of extract.

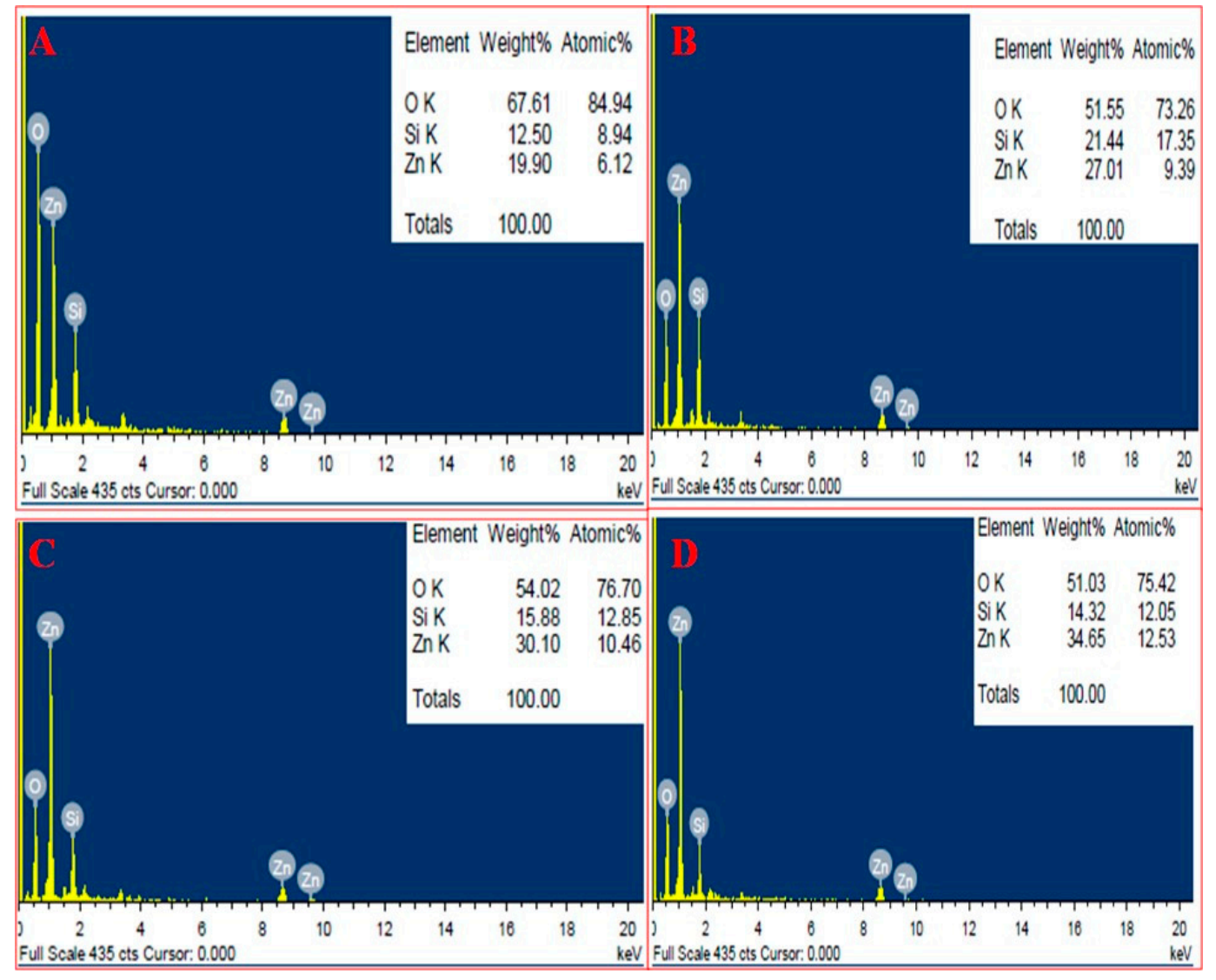

Figure 4. EDAX of BM-ZnO NPs at different concentration of extract. (A) $10 \mathrm{~mL}$ extract, (B) $20 \mathrm{~mL}$ extract, (C) $30 \mathrm{~mL}$ extract, and (D) $40 \mathrm{~mL}$ extract. 


\subsection{TEM Analysis of Synthesized $\mathrm{ZnO} N P S$}

The average size of nanoparticles at $40 \mathrm{~mL}$ extract concentration was $25 \mathrm{~nm}$ as calculated by ImageJ software (Figure 5). The particle size at 10, 20, and $30 \mathrm{~mL}$ extract concentrations were not measured as there were greater aggregation and clumping of nanoparticles.

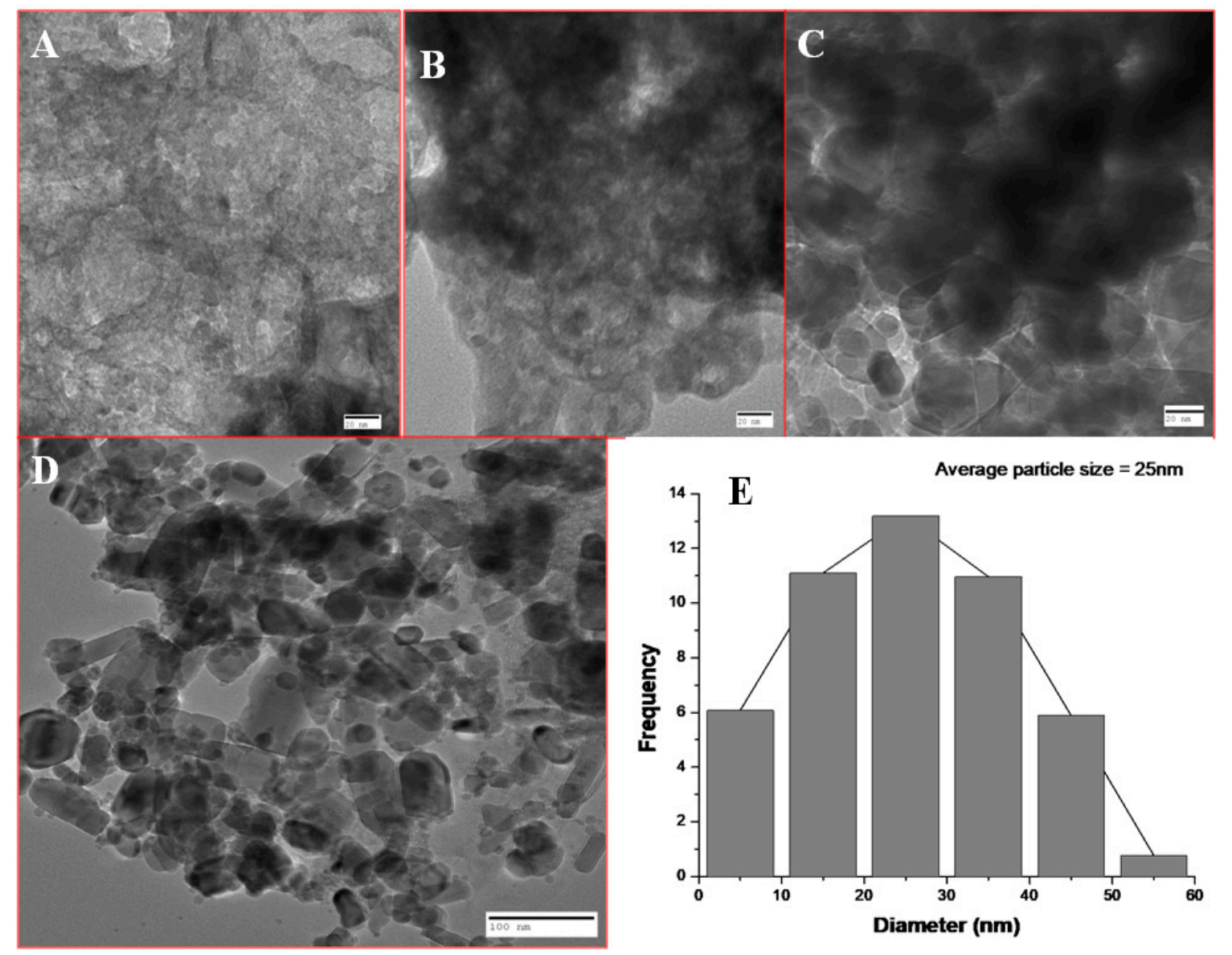

Figure 5. TEM of BM-ZnO NPs at different concentration of extract. (A) $10 \mathrm{~mL}$ extract, (B) $20 \mathrm{~mL}$ extract, (C) $30 \mathrm{~mL}$ extract, (D) $40 \mathrm{~mL}$ extract, (E) Average size of the nanoparticles at $40 \mathrm{~mL}$ extracts.

\subsection{Antibiotic Resistance Pattern of Clinical Isolates of P. aeruginosa}

All the 10 isolates of P. aeruginosa were resistant to Amikacin (Ak, $30 \mu \mathrm{g})$, cefepime (Cpm, $30 \mu \mathrm{g})$, sparfloxacin (Spx, $5 \mu \mathrm{g}$ ), piperacillin (Pi, $100 \mu \mathrm{g})$, Levofloxacin (Le, $5 \mu \mathrm{g})$, piperacilin-tazobactum (Pit, 100/10 $\mu \mathrm{g}$ ), imipenem (Ipm, $10 \mu \mathrm{g}$ ), tobramycin (Tob, $10 \mu \mathrm{g}$ ), nitrofurantoin (Nit, $300 \mu \mathrm{g}$ ), and ceftazidime (Caz, $30 \mu \mathrm{g})$ antibiotics.

\subsection{Minimum Inhibitory Concentration (MIC)}

MIC value of BM-ZnO NPs against standard PAO1 was found to be $1600 \mu \mathrm{g} / \mathrm{mL}$, whereas the MIC value ranged from 1600-3200 $\mu \mathrm{g} / \mathrm{mL}$ for clinical isolates obtained from different sources (Table 1). Therefore, 300, 200, and $100 \mu \mathrm{g} / \mathrm{mL}$ were considered as sub MIC.

Table 1. MIC values of BM-ZnO NPs against P. aeruginosa (PAO1 and clinical isolates).

\begin{tabular}{ccc}
\hline Isolates & MIC $\left(\mu \mathbf{g ~ m L}^{-\mathbf{1}}\right)$ & Source \\
\hline PAO1 & 1600 & Standard \\
\hline P1 & 3200 & Pus \\
\hline
\end{tabular}


Table 1. Cont.

\begin{tabular}{ccc}
\hline Isolates & MIC $\left(\mu \mathbf{g ~ m L}^{-\mathbf{1}}\right)$ & Source \\
\hline P2 & 3200 & Pus \\
\hline P3 & 1600 & Pus \\
\hline P4 & 3200 & Pus \\
\hline P5 & 1600 & Pus \\
\hline P6 & 3200 & Urine \\
\hline P7 & 3200 & Pus \\
\hline P8 & 3200 & Urine \\
\hline P9 & 1600 & Pus \\
\hline P10 & 3200 & Urine \\
\hline
\end{tabular}

\subsection{Inhibition of Production of Quorum-Mediated Virulence Factors}

In case of PAO1, pyocyanin level decreased by $63.3 \%$ at $300 \mu \mathrm{g} / \mathrm{mL}$, whereas $44.7 \%$ and $28.3 \%$ reduction was observed at $200 \mu \mathrm{g} / \mathrm{mL}$ and $100 \mu \mathrm{g} / \mathrm{mL}$, respectively (Figure 6). The reduction in the level of pyocyanin for clinical isolates after treatment with $300 \mu \mathrm{g} / \mathrm{mL}$ of BM-ZnO NPs was $58.5 \%$ to $67.7 \%$. The lower doses of $\mathrm{ZnO}$ NPs viz. 200 and $100 \mu \mathrm{g} / \mathrm{mL}$ also reduced the level of pyocyanin by $45.08 \%$ to $54.3 \%$ and $23.6 \%$ to $36.7 \%$, respectively (Figure 7). Protease concentration for PAO1 reduced by $35.4 \%$ at $300 \mu \mathrm{g} / \mathrm{mL}$, whereas $21.5 \%$ reduction was observed at $200 \mu \mathrm{g} / \mathrm{mL}$. The sub MIC level of $100 \mu \mathrm{g} / \mathrm{mL}$ showed statistical insignificant results. In case of clinical isolates protease concentration decreased by $24.1 \%$ to $39.3 \%$ at $300 \mu \mathrm{g} / \mathrm{mL}$ and at lower concentration of $\mathrm{ZnO} N$ Ps viz. $200 \mu \mathrm{g} / \mathrm{mL}$ $11.2 \%$ to $30.3 \%$ reductions were observed (Figure 8 ). $100 \mu \mathrm{g} / \mathrm{mL}$ of concentration showed statistical insignificant results for all the isolates. Hemolytic activity of the isolates was also affected by ZnO NPs; PAO1 showed $45 \%$ reduction in the hemolytic activity at highest sub MIC level $(300 \mu \mathrm{g} / \mathrm{mL})$. However, at lower concentration i.e., 200 and $100 \mu \mathrm{g} / \mathrm{mL}$, ZnO NPs reduced the hemolytic activity by $29.5 \%$ and $19.1 \%$, respectively (Figure 9); whereas for clinical isolates $300 \mu \mathrm{g} / \mathrm{mL}$ of $\mathrm{ZnO}$ NPs successfully reduced the level of hemolytic activity in the range of $29.6 \%$ to $52.9 \%$ followed by $15.3 \%$ to $38.2 \%$ for $200 \mu \mathrm{g} / \mathrm{mL}$ and $14.1 \%$ to $29.4 \%$ at $100 \mu \mathrm{g} / \mathrm{mL}$, respectively (Supplementary Materials Tables S1-S4).

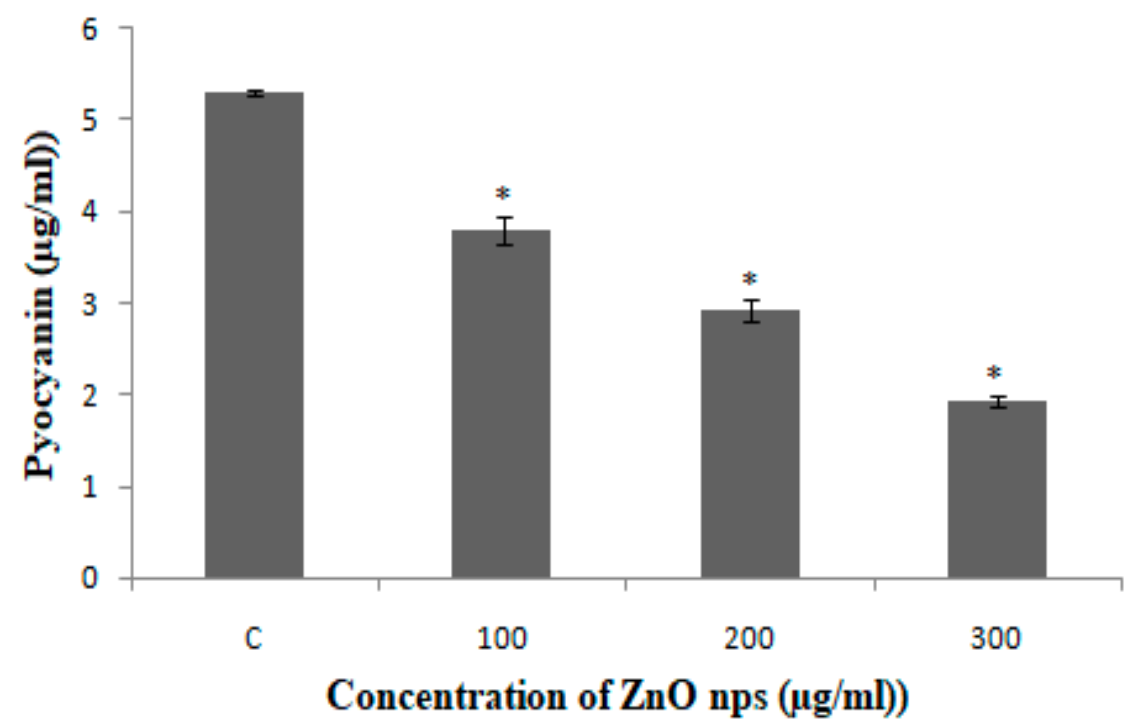

Figure 6. PAO1 treated with different concentration BM-ZnO NPs. Errors bars are indicative of standard deviation $( \pm) ;{ }^{*}$ represents significance when $p \leq 0.05 \& C$ represent control group. 


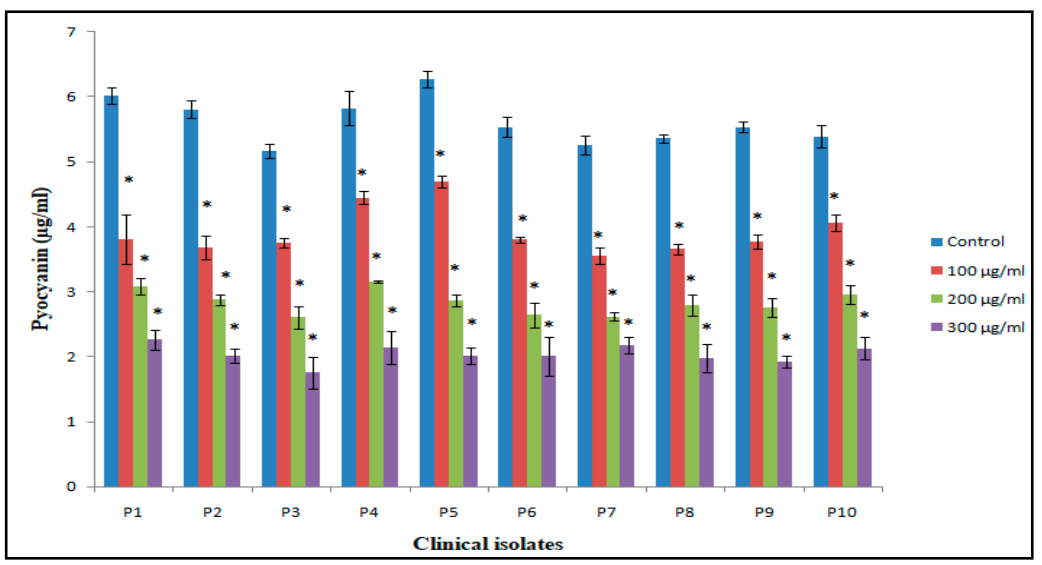

Figure 7. Bar graphs of clinical isolates of P. aeruginosa representing pyocyanin production $(\mu \mathrm{g} / \mathrm{mL})$ at three different concentrations $(100,200,300 \mu \mathrm{g} / \mathrm{mL})$ of BM-ZnO NPs along with control as untreated. * represents significance when $p \leq 0.05 / \mathrm{mL}$; Error bars represent standard deviation.

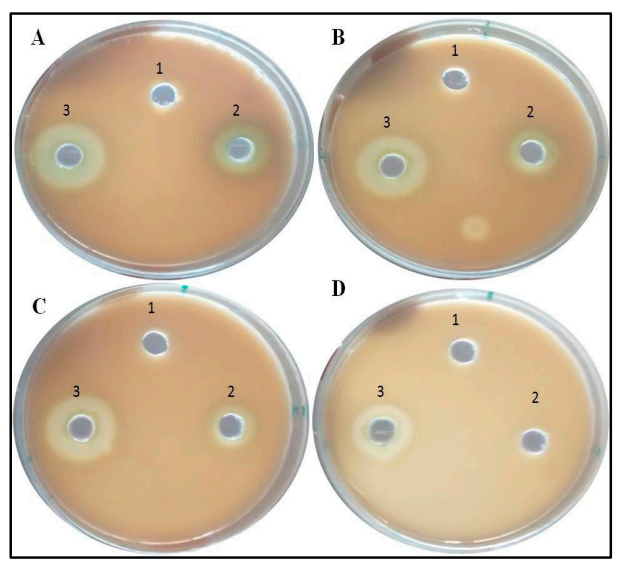

Figure 8. Images representative of Anti-proteolytic effect of ZnO NPs. Zone size decreases as the concentration increases. Well (1) represents Nutrient Broth, well (2) PAO1 culture, and well (3) Clinical isolate. (A) Control, (B) $100 \mu \mathrm{g} / \mathrm{mL}$ of $\mathrm{ZnO}$ amended, (C) $200 \mu \mathrm{g} / \mathrm{mL}$ of $\mathrm{ZnO}$ amended, (D) $300 \mu \mathrm{g} / \mathrm{mL}$ of $\mathrm{ZnO}$ amended.

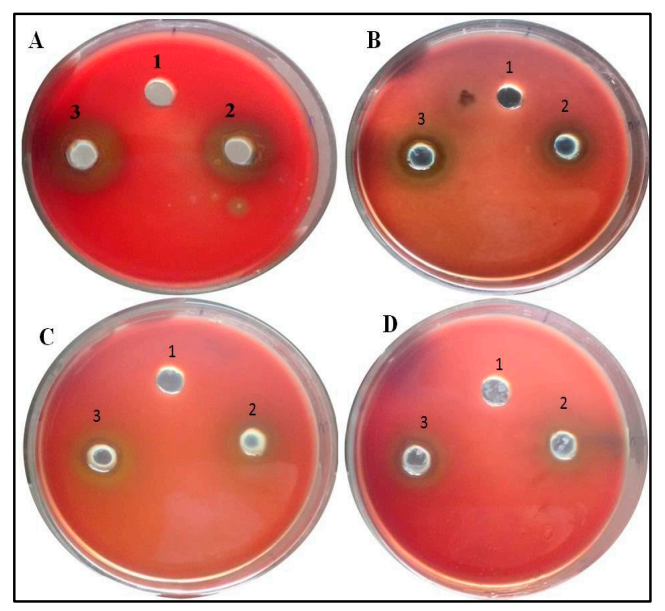

Figure 9. Images representative of Anti-hemolysis effect of $\mathrm{ZnO}$ NPs. Zone size decreases as the concentration increases. Well (1) represents Nutrient Broth, well (2) PAO1 culture and well (3) Clinical isolate. (A) Control, (B) $100 \mu \mathrm{g} / \mathrm{mL}$ of $\mathrm{ZnO}$ amended, (C) $200 \mu \mathrm{g} / \mathrm{mL}$ of $\mathrm{ZnO}$ amended, (D) $300 \mu \mathrm{g} / \mathrm{mL}$ of $\mathrm{ZnO}$ amended. 


\subsection{TEM Analysis Showing Localization of BM-ZnO-NPs at Sub MIC Concentration}

Figure 10A-D represents the localization of BM-ZnO-NPs inside the bacterial cells at sub MIC concentration i.e., 100, 200 and $300 \mu \mathrm{g} / \mathrm{mL}$, respectively. It was observed that as the concentration of nanoparticles increased, there was a greater accumulation of NPs inside the cells.

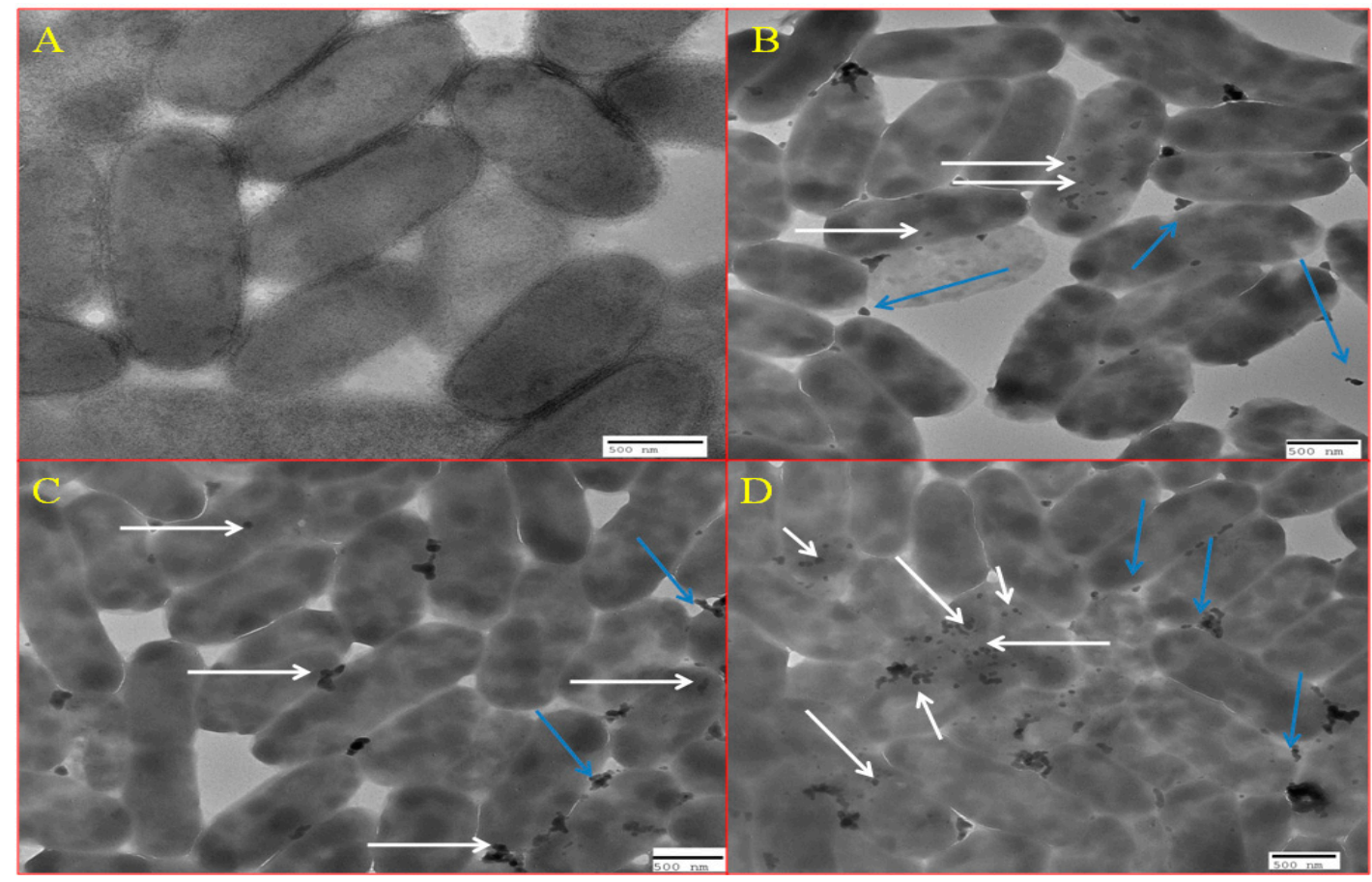

Figure 10. TEM showing internalization of ZnO NPs. (A) Control, (B) at $100 \mu \mathrm{g} / \mathrm{mL}$ of $\mathrm{ZnO}$, (C) at $200 \mu \mathrm{g} / \mathrm{mL}$ of $\mathrm{ZnO}$, and (D) $300 \mu \mathrm{g} / \mathrm{mL}$ of $\mathrm{ZnO}$ NPs. White arrows marks the internalized nanoparticles whereas blue arrow marks the nanoparticles which are outside the cells.

\section{Discussion}

P. aeruginosa is a notorious pathogen causing nosocomial infections in individuals whose immune system has been weaken more specifically in burn patients [31,32]. It rarely causes community acquired infection in immuno-competent patients that is the reason it is known as an opportunistic pathogen. It is also evident from the literature that $P$. aeruginosa produces virulence factors and maintains multi drug resistance through quorum sensing [7]. Therefore the induction of quorum sensing inhibitors could be the key aspect in the anti-pathogenicity of this organism [33].

The present study demonstrates that $\mathrm{ZnO}$ NPs possess quorum-mediated anti-virulence property against the standard strain PAO1 as well as against multi drug resistant clinical isolates of P. aeruginosa.

\subsection{Effect of Varying Volume of Extract on the Synthesis of Nanoparticles}

Biosynthesized BM-ZnO NPs was characterized by different techniques viz. FTIR, SEM, EDAX, and TEM. FTIR analysis showed the formation of different bonds between extract and ZnO NPs. These bonds are remarkable features of the bio-molecules involved in the capping and stabilization of nanoparticles. SEM and TEM analysis showed distribution of particles and its aggregation, it is evident that higher proportion vs. nanoparticles posses more capping and stabilizing agent due to which greater uniformity in terms of shape and size was obtained, the fact is supported by the SEM and TEM analysis of ZnO NPs where greater uniformity was seen as the concentration of extract increased (Figures 3 and 5). In other words, a greater amount of extract reduced precursor molecules (Zinc nitrate), which was confirmed by the EDAX analysis, which showed that a greater amount of zinc was obtained at higher extract concentration (Figure 4). Our results are also in agreement with previous 
studies which showed that on increasing extract concentration greater homogeneity regarding shape and size was obtained for zinc nanoparticles [34] and silver nanoparticles [35].

\subsection{Effect of Bio Synthesized ZnO NPs on QS Mediated Virulence Factors}

Pyocyanin, a blue, green phenazine pigment specifically produced by the P. aeruginosa [27], is directly operated by QS [1,36]. Pyocyanin, besides being the hallmark of $P$. aeruginosa, is also a secondary metabolite that leads to the severe toxic effect in combination with its precursor phenazine-1-carboxylic acid [37]. The damage caused by these two molecules accounts for the apoptosis of neutrophils and neutrophil mediated defensive mechanism [38]. BM-ZnO NPs decreased the production of pyocyanin in dose dependent manner as we observed that at the highest dose of $300 \mu \mathrm{g} / \mathrm{mL}$ of $\mathrm{ZnO}$ NPs there was the greatest decrease in production of pyocyanin as compared to the untreated cells $(p \leq 0.05)$. P. aeruginosa in order to maintain its pathogenicity and to further spread its infection secretes the hydrolytic enzymes such as hemolysin and proteases [39]. Proteases or peptidases are enzymes that degrade proteins and peptides by hydrolyzing the peptide bonds [40]. Proteins being the building block of cells when degraded by the protease affect the individual cells and further enhance the infection. Hemolysins leads to the lysis of host cell, different hemolysin such as Phospholipase and lecithinase acts in combination to break down lipids and lecithin and these proteins further encourage invasions by inducing cytotoxic effects on host cells [41]. BM-ZnO-NPs as shown in the result section decreased the production of hydrolytic enzymes viz. proteases and hemolysin. Maximum affect was seen at the highest dose $(300 \mu \mathrm{g} / \mathrm{mL})$ for PAO1 as well as for clinical isolates. Previous reports focused on to the antimicrobial aspect supporting the bacteriostatic or bactericidal approach [42] but very few reports focused on the antivirulence aspect supporting quorum quenching. Our results are in agreement with the previous work done by Garcia-Lara et al. [43] who showed that $\mathrm{ZnO}$ NPs affected the pyocyanin and elastase in P. aeruginosa at $100 \mu \mathrm{g} / \mathrm{mL}$. They also proposed that virulence factors production and biofilm was due to quorum quenching effect of nanoparticles and not due to bacteriostatic or bactericidal effect. In another study, Saleh et al. [44] also reported that ZnO NPs can be effectively used as a quorum sensing inhibitor against $P$. aeruginosa infection and can be used as an alternative to conventional antimicrobials. Naseer Al Shabib [45] showed the similar results where Nigella sativa mediated ZnO NPs effectively inhibited the quorum regulated virulence factors in P. aeruginosa at sub MIC level.

Further, we are also of the opinion that due to the localization of BM-ZnO NPs inside the bacterial some mechanism would have been disturbed because of which virulence efficacy lowered down. Furthermore, the TEM analysis Figure 10A-D revealed that as the concentration of nanoparticles increased there was a greater accumulation of nanoparticles inside the cell and greater decrease in the virulence efficacy.

\section{Conclusions}

The biosynthesized ZnO NPs at sub MIC level successfully inhibited the production of quorum sensing mediated virulence factors in P. aeruginosa. We are of opinion that ZnO NPs have quorum quenching effect due to which the virulence efficacy of P. aeruginosa lowered. Zinc oxide nanoparticles might have affected the QS mediated strategy either by arresting the production of QS molecules or by interacting with the QS molecules making them unidentified for the cell machinery and neutralizing their effect. Furthermore, studies on molecular aspect need to be done to know the exact mechanism involved in anti-virulence strategy, the studies on gene level could be a better option for knowing interaction between nanoparticles and gene expression.

Supplementary Materials: The following are available online at http://www.mdpi.com/2079-6382/9/5/260/s1, Table S1: Effect of different concentration of BM-ZnO NPs on different virulence factors of PAO1., Table S2: Effect of different concentration of BM-ZnO NPs on pyocyanin production by clinical isolates of P. aeruginosa., Table S3: Effect of different concentration of BM-ZnO NPs on protease production by clinical isolates of P. aeruginosa., Table S4: Effect of different concentration BM-ZnO NPs on hemolysis production by clinical isolates of P. aeruginosa. 
Author Contributions: Conceptualization, S.G.A., M.A.A. (Mohammad Azam Ansari) and H.M.K.; Data curation, M.A.A. (Mohammad A. Alzohairy) and S.M.M.A.; Formal analysis, M.A.A. (Mohammad Azam Ansari), M.N.A., S.AlYahya, M.J., H.M K. and S.M.M.A.; Investigation, S.G.A. and M.J.; Methodology, S.G.A. and M.J.; Resources, S.A. and S.M.M.A.; Software, M.A.A. (Mohammad A. Alzohairy), H.M.K. and S.M.M.A.; Supervision, M.A.A. (Mohammad Azam Ansari) and H.M.K.; Validation, M.N.A. and S.A.; Visualization, S.M.M.A. and M.A.A. (Mohammad A. Alzohairy); Writing-original draft, S.G.A. and M.A.A. (Mohammad Azam Ansari); Writing-review \& editing, S.G.A., M.A.A. (Mohammad Azam Ansari), M.A.A. (Mohammad A. Alzohairy), M.N.A., M.J., H.M.K., S.A. and S.M.M.A. All authors have read and agreed to the published version of the manuscript.

Funding: This work was funded by Deanship of Scientific Research Project number (2019-091-IRMC), Imam Abdulrahman Bin Faisal University, Dammam, Saudi Arabia.

Acknowledgments: The authors would like to acknowledge AIRF, Jawaharlal Nehru University, New Delhi, India, Aligarh Muslim University, Aligarh U.P., India and Institute for Research \& Medical Consultations (IRMC), Imam Abdulrahman Bin Faisal University, Dammam, Saudi Arabia for providing research facilities for recording SEM \& TEM.

Conflicts of Interest: The authors declare that they have no conflict of interest.

\section{References}

1. De-Kievit, T.R.; Iglewski, B.H. Bacterial quorum sensing in pathogenic relationships. Infect. Immun. 2000, 68, 4839-4849. [CrossRef]

2. Banu, O.; Bleotu, C.; Chifiriuc, M.C.; Savu, B.; Stanciu, G.A.; Antal, C.; Alexandrescu, M.; Lazar, V. Virulence factors of Staphylococcus aureusand Pseudomonas aeruginosastrains involved in the etiology of cardiovascular infections. Biointerface Res. Appl. Chem. 2011, 1, 72-77.

3. Saviuc, C.; Grumezescu, A.M.; Holban, A.; Bleotu, C.; Chifiriuc, C.; Paul, B.; Lazar, V. Phenotypical studies of raw and nanosystem embedded Eugenia carryophyllatabuds essential oil effect on Pseudomonas aeruginosaand Staphylococcus aureusstrains. Biointerface Res. Appl. Chem. 2011, 1, 111-118.

4. Andronescu, E.; Grumezescu, A.M.; Ficai, A.; Gheorghe, I.; Chifiriuc, M.; Mihaiescu, D.E.; Lazar, V. In vitro efficacy of antibiotic magnetic dextran microspheres complexes against Staphylococcus aureusand Pseudomonas aeruginosastrains. Biointerface Res. Appl. Chem. 2012, 2, 332-338.

5. Su, H.C.; Ramkissoon, K.; Doolittle, J.; Clark, M.; Khatun, J.; Secrest, A.; Wolfgang, M.C.; Gidding, M.C. The development of ciprofloxacin resistance in Pseudomonas aeruginosainvolves multiple response stages and multiple proteins. Antimicrob. Agents Chemother. 2010, 54, 4626-4635. [CrossRef]

6. Juan, C.; Zamorano, L.; Perez, J.L.; Ge, Y.; Oliver, A. And on behalf of the Spanish Group for the Study of Pseudomonas and the Spanish Network for Research in Infectious Diseases Activity of a new anti pseudomonal cephalosporin, CXA-101 (FR264205), against carbapenem resistant and multi drug resistant Pseudomonas aeruginosaclinical strains. Antimicrob. Agents Chemother. 2010, 54, 846-851.

7. Van-Delden, C.; Iglewski, B.H. Cell-to-cell signaling and Pseudomonas aeruginosainfections. Emerg. Infect. Dis. 1998, 4, 551-560.

8. Antunes, L.C.M.; Ferreira, R.B.R.; Buckner, M.M.C.; Finlay, B.B. Quorum sensing in bacterial virulence. Microbiology 2010, 156, 2271-2282. [CrossRef]

9. Defoirdt, T.; Boon, N.; Bossier, P. Can bacteria evolve resistance to quorum sensing disruption? PLoS Pathog. 2010, 6, e1000989. [CrossRef]

10. Rasko, D.A.; Sperandio, V. Anti-virulence strategies to combat bacteria-mediated disease. Nat. Rev. Drug Discov. 2010, 9, 117-128. [CrossRef]

11. Albrecht, M.A.; Evans, C.W.; Raston, C.L. Green chemistry and the health implications of nanoparticles. Green Chem. 2006, 8, 417-432. [CrossRef]

12. Duran, N.; Marcato, P.D.; Alves, O.L.; De Souza, G.I.H.; Esposito, E. Mechanistic aspects of biosynthesis of silver nano particles by several Fusariumoxysporum strains. J. Nanobiotecnol. 2005, 3, 1-7.

13. Ingle, A.; Gade, A.; Pierrat, S.; Sonnichsen, C.; Mahendra, R. Mycosynthesis of silver nanoparticles using the fungus Fusariumacuminatumand its activity against some human pathogenic bacteria. Curr. Nanosci. 2008, 4, 141-144. [CrossRef]

14. Taylor, P.L.; Ussher, A.L.; Burrell, R.E. Impact of heat on nanocrystalline silver dressings. Part I: Chemical and biological properties. Biomaterials 2005, 26, 7221-7229. [CrossRef] [PubMed]

15. Dhage, S.R.; Pasricha, R.; Ravi, V. Synthesis of fine particles of $\mathrm{ZnO}$ at $100{ }^{\circ}$ C. Mater. Lett. 2005, 59, 779-781. [CrossRef] 
16. Stoimenov, P.K.; Klinger, R.L.; Marchin, G.L.; Klabunde, K.J. Metal oxide nanoparticles as bactericidal agent. Langmuir 2002, 18, 6679-6686. [CrossRef]

17. Fu, L.; Liu, Z.; Liu, Y.; Han, B.; Hu, P.; Cao, L.; Zhu, D. Beaded Cobalt oxide nanoparticle along carbon nanotubes: Towards more highly integrated electronic devices. Adv. Mater. 2005, 17, 217-221. [CrossRef]

18. Kharissova, O.V.; Dias, H.V.R.; Kharisov, B.I.; Perez, B.O.; Jimenez Perez, V.M. The Greener Synthesis of Nanoparticles. Trends Biotechnol. 2013, 31, 240-248. [CrossRef]

19. Shankar, S.S.; Rai, A.; Ahmad, A.; Sastry, M. Rapid synthesis of Au, Ag, and bimetallic Au core-Ag shell nanoparticles using Neem (Azadirachta indica) leaf broth. J. Colloid Interface Sci. 2004, 275, 496-502. [CrossRef]

20. Ali, S.G.; Khan, H.M.; Jalal, M.; Ansari, M.A.; Mahdi, A.A.; Ahmad, M.K. Green synthesis of silver nanoparticles using the leaf extract of Putranjiva roxburghii wall. and their antimicrobial activity. Asian J. Pharm. Clin. Res. 2015, 8, 335-338.

21. Ali, S.G.; Ansari, M.A.; Alzohairy, M.A.; Alomary, M.N.; AlYahya, S.; Jalal, M.; Khan, H.M.; Asiri, S.M.M.; Ahmad, W.; Mahdi, A.A.; et al. Biogenic Gold Nanoparticles as Potent Antibacterial and Antibiofilm Nano-Antibiotics against Pseudomonas aeruginosa. Antibiotics 2020, 9, 100. [CrossRef] [PubMed]

22. Roopan, S.M.; Rohita; Madhumitha, G.; Rahuman, A.A.; Kamaraj, C.; Bharathi, A.; Suredra, T.V. Low-cost and eco-friendly phyto-synthesis of silver nanoparticles using Cocosnuciferacoir extract and its larvicidal activity. Ind. Crops Prod. 2012, 43, 631-635. [CrossRef]

23. Ali, S.G.; Ansari, M.A.; Khan, H.M.; Jalal, M.; Mahdi, A.A.; Cameotra, S.S. Crataeva nurvala nanoparticles inhibit virulence factors and biofilm formation in clinical isolates of Pseudomonas aeruginosa. J. Basic Microbiol. 2017, 57, 193-203. [CrossRef] [PubMed]

24. Ali, S.G.; Ansari, M.A.; Khan, H.M.; Jalal, M.; Mahdi, A.A.; Cameotra, S.S. Antibacterial and antibiofilm potential of green synthesized silver nanoparticles against imipenem resistant clinical isolates of P. aeruginosa. Bio. Nano Sci. 2018, 8, 544-553. [CrossRef]

25. Baig, U.; Gondal, M.A.; Ansari, M.A.; Akhtar, S. Facile synthesis, characterization and antibacterial activity of nanostructured palladium loaded silicon carbide. Ceram. Int. 2018, 44, 16908-16914. [CrossRef]

26. Clinical Laboratory Standards Institute. Performance Standards for Antimicrobial Susceptibility Testing, 22nd ed.; Informational Supplement Document M100-S22; Clinical Laboratory Standards Institute: Wayne, PA, USA, 2012.

27. Essar, D.W.; Eberly, L.; Hadero, A.; Crawford, I.P. Identification and characterization of genes for a second anthranilate synthase in Pseudomonas aeruginosa: Interchangeability of the two anthranilate synthases and evolutionary implications. J. Bacteriol. 1990, 172, 884-900. [CrossRef] [PubMed]

28. Quiblier, C.; Zinkernagel, A.S.; Schuepbach, R.A.; Berger-Bächi, B. Contribution of SecDF to Staphylococcus aureus resistance and expression of virulence factors. BMC Microbiol. 1990, 11, 72. [CrossRef]

29. Jalal, M.; Ansari, M.A.; Alzohairy, M.A.; Ali, S.G.; Khan, H.M.; Almatroudi, A.; Siddiqui, M.I. Anticandidal activity of biosynthesized silver nanoparticles: Effect on growth, cell morphology, and key virulence attributes of Candida species. Int. J. Nanomed. 2019, 14, 4667. [CrossRef]

30. Saghalli, M.; Bidoki, S.K.; Jamali, A.; Bagheri, H.; Ghaemi, E.A. Sub-minimum inhibitory concentrations of Zinc Oxide Nanoparticles Reduce the Expression of the Staphylococcus aureus Alpha-Hemolysin. Indian J. Pharm. Sci. 2017, 78, 763-768.

31. Costerton, J.W.; Stewart, P.S.; Greenberg, E.P. Bacterial biofilms: A common cause of persistent infections. Science 1999, 284, 1318-1322. [CrossRef]

32. Whiteley, M.; Bangera, M.G.; Bumgarner, R.E.; Parskek, M.R.; Teitzel, G.M.; Lory, S.; Greenberg, E.P. Gene expression in Pseudomonas aeruginosa biofilms. Nature 2001, 413, 860-864. [CrossRef] [PubMed]

33. Fothergill, J.L.; Winstanley, C.; James, C.E. Novel therapeutic strategies to counter Pseudomonas aeruginosainfections. Expert Rev. Anti Infect. Ther. 2012, 10, 219-235. [CrossRef] [PubMed]

34. Nava, O.J.; Luque, P.A.; Gomez-Gutierrez, C.M.; Vilchis-Nestor, A.R.; Castro-Beltran, A.; Mota-Gonzalez, M.L.; Olivas, A. Influence of Camellia sinensisextract on Zinc Oxide nanoparticlegreen synthesis. Mol. Struct. 2017, 1134, 121-125. [CrossRef]

35. Khalil, M.M.H.; Ismail, E.H.; El-Baghdady, K.Z.; Mohamed, D. Green synthesis of silver nanoparticles using olive leaf extract and its antibacterial activity. Arab. J. Chem. 2014, 7, 1131-1139. [CrossRef]

36. Karatuna, O.; Yagci, A. Analysis of quorum sensing dependent virulence factor production and its relationship with antimicrobial susceptibility in Pseudomonas aeruginosarespiratory isolates. Clin. Microbiol. Infect. 2010, 16, 1770-1775. [CrossRef] 
37. Fothergill, J.L.; Panagea, S.; Hart, C.A.; Walshaw, M.J.; Pitt, T.L.; Winstanlet, C. Widespread pyocyanin over production among isolates of a cystic fibrosis epidemic strain. BMC Microbiol. 2007, 7, 45. [CrossRef]

38. Usher, L.R.; Lawson, R.A.; Geary, I.; Taylor, C.J.; Bingle, C.D.; Taylor, G.W.; Whyte, M.K. Induction of neutrophil apoptosis by the Pseudomonas aeruginosaexotoxin pyocyanin: A potential mechanism of persistent infection. J. Immunol. 2002, 168, 1861-1868. [CrossRef]

39. Gupta, R.K.; Setia, S.; Harjai, K. Expression of quorum sensing and virulence factors is interlinked in P. aeruginosa: An in vitro approach. Am. J. Biomed. Sci. 2011, 3, 116-125. [CrossRef]

40. Barrett, A.J.; Woessner, J.F.; Rawlings, N.D. Handbook of Proteolytic Enzymes, 2nd ed.; Academic Press: London, UK, 2004.

41. Wilson, R.; Pitt, T.; Taylor, G.; Watson, D.; Mac Dermot, J.; Sykes, D.; Roberts, D.; Cole, P. Pyocyanin and 1-hydroxyphenazine produced by Pseudomonas aeruginosainhibit the beating of human respiratory cilia in vitro. J. Clin. Investig. 1987, 79, 221-229. [CrossRef]

42. Sirelkhatim, A.; Mahmud, S.; Seeni, A.; Kaus, N.H.; Ann, L.C.; Bakhori, S.K.; Hasan, H.; Mohamad, D. Review on zinc oxide nanoparticles: Antibacterial activity and toxicity mechanism. Nano-Micro Lett. 2015, 7, $219-242$. [CrossRef]

43. Garcia-Lara, B.; Saucedo-Mora, M.A.; Roldan-Sanchez, J.A.; Perez-Eretza, B.; Ramasamy, M.; Lee, J.; Coria-Jimenez, R.; Tapia, M.; Varela-Guerrero, V.; Garcia-Contreras, R. Inhibition of quorum-sensingdependent virulence factorsand biofilm formation of clinical and environmental Pseudomonas aeruginosa strains by ZnO nanoparticles. Lett. Appl. Microbiol. 2015, 61, 299-305. [CrossRef] [PubMed]

44. Saleh, M.M.; Sadeq, R.A.; Abdel Latif, H.K.; Abbas, H.A.; Askoura, M. Zinc oxide nanoparticles inhibits quorum sensing and virulence in Pseudomonas aeruginosa. Afr. Health Sci. 2019, 19, 2043-2055. [CrossRef] [PubMed]

45. Al-Shabib, N.A.; Husain, F.M.; Ahmed, F.; Khan, R.A.; Ahmad, I.; Alsharaeh, E.; Khan, M.S.; Hussain, A.; Rehman, M.T.; Yusuf, M.; et al. Biogenic synthesis of Zinc oxide nanostructures from Nigella sativa seed: Prospective role as food packaging material inhibiting broad-spectrum quorum sensing and biofilm. Sci. Rep. 2016, 6, 36761. [CrossRef] [PubMed] 